\title{
Maturational changes in opioidergic control of luteinizing hormone and follicle-stimulating hormone in ram lambs
}

\author{
N. C. Rawlings, I. J. Churchill, W. D. Currie and I. B. J. K. Joseph \\ Department of Veterinary Physiological Sciences, Western College of Veterinary Medicine, \\ University of Saskatchewan, Saskatoon, Saskatchewan, Canada S7N OWO
}

\begin{abstract}
Summary. Stimulation by naloxone, an opioid antagonist, of luteinizing hormone (LH) and follicle-stimulating hormone (FSH) secretion was examined in spring-born crossbred ram lambs raised under natural photoperiod. Vehicle $(n=6)$ or $1 \mathrm{mg}$ naloxone $/ \mathrm{kg}$ vehicle $(n=6)$ was injected (i.m.) 3 times at 2 -h intervals at 5,10 and 15 weeks of age and 4 times at 2-h intervals at 20,25, 30 and 35 weeks of age. Blood samples were taken every $12 \mathrm{~min}$ for $6 \mathrm{~h}$ at 5,10 and 15 weeks of age and for $8 \mathrm{~h}$ at 20 , 25,30 and 35 weeks of age. Naloxone had no effect on age at sexual maturity (controls $239 \pm 23$ days; naloxone $232 \pm 33$ days). The only significant $(P<0.05)$ effect of naloxone on FSH was a greater pulse amplitude in 10 -week-old treated lambs than in control lambs. Naloxone treatment resulted in greater LH pulse amplitude at 5 and 10 weeks of age $(P<0.05)$, lower basal serum concentration of $\mathrm{LH}$ at 10 weeks of age $(P<0.05)$, greater LH pulse frequency at 25 weeks of age $(P<0.05)$, and greater mean serum concentrations of LH, basal $\mathbf{L H}$ and $\mathrm{LH}$ pulse amplitude at 35 weeks of age $(P<0.01)$ than in the controls.

In both groups of lambs, mean and basal FSH, and LH and FSH pulse amplitude were highest at 5 weeks of age and fell with age. LH pulse amplitude was lowest at 35 weeks of age $(P<0.05)$. Mean and basal LH were higher at 10 weeks of age than at all other times in the control lambs only. In control and treated lambs, FSH pulse frequency did not change with age, but LH pulse frequency was high at 35 weeks of age $(P<0.05)$ and mean serum concentrations of testosterone rose with age $(P<0.05)$.

We conclude that (i) opioidergic suppression of gonadotrophin secretion occurs in young ram lambs when testosterone concentrations are low, but diminishes as the lamb grows, only to be re-established, primarily for $\mathrm{LH}$, as the animal matures and testosterone reaches adult concentrations and (ii) attainment of sexual maturity in ram lambs is marked by changes in the pattern of episodic LH secretion, pulse frequency increasing markedly.
\end{abstract}

Keywords: ram lamb; naloxone; LH; FSH

\section{Introduction}

In intact rams and testosterone-treated wethers, naloxone increases and morphine reduces circulating concentrations of LH (Ebling \& Lincoln, 1985; Schanbacher, 1985; Lincoln et al., 1987). Morphine and naloxone also influence circulating LH concentrations in wethers not treated with steroids, but the effects are neither as consistent nor as marked (Schanbacher, 1985; Lincoln et al., 1987). Season of year also influences LH responses to opioid agonists and antagonists, the greatest sensitivity being during the breeding season (Ebling \& Lincoln, 1985; Lincoln et al., 1987). The nature of the role of the opioids in controlling the pattern of basal LH secretion and the frequency and amplitude of pulse secretion is unclear. In addition, the role of endogenous opioids in 
controlling FSH secretion in rams has not been investigated. There is some evidence that long-term treatment with naltrexone in prepubertal male rats may enhance testicular growth, indicating an effect on gonadotrophin secretion (Zagon \& McLaughlin, 1984). However, observations on the effects of naloxone and morphine on serum LH concentrations in prepubertal rats are confusing. It is not clear whether endogenous opioids are important regulators of sexual maturation in the male (Ieiri et al., 1978; Bhanot \& Wilkinson, 1983; Cicero et al., 1986). The present study determined the effects of naloxone on tonic gonadotrophin secretion during reproductive development in ram lambs, to assess the importance of endogenous opioid peptidergic tone in controlling the onset of sexual maturation.

\section{Materials and Methods}

Animals. Six pairs of spring-born ram lambs, matched for weight and age and of mixed breeds were housed in sheltered dry lots and raised under natural photoperiod. Creep feed was available from 1 week of age and the lambs were weaned at 7 weeks of age and housed in a separate pen in proximity to ewe lambs. Commercial mixed feeds were used according to NRC (National Research Council, 1985) recommendations for replacement rams. Mixed minerals, salt, water and lucerne-brome hay were freely available.

Treatment and sampling. Six lambs received normal saline (control) and 6 were treated with $1 \mathrm{mg}$ naloxone $/ \mathrm{kg}$ (E. I. DuPont de Nemours and Co., Garden City, NY, USA) in saline (i.m.) 3 times at 2-h intervals at 5, 10 and 15 weeks of age and 4 times at 2-h intervals at 20,25,30 and 35 weeks of age. The treatment period was shorter for younger lambs, to reduce handling and blood loss. The dose of naloxone had previously been shown to raise serum LH concentrations in cyclic ewes (Currie \& Rawlings, 1987). Blood samples ( $3 \mathrm{ml}$ ) were taken every $12 \mathrm{~min}$ for $6 \mathrm{~h}$ starting at the first naloxone/saline injection in the young lambs at 5,10 and 15 weeks of age and for $8 \mathrm{~h}$ in lambs at 20 , 25,30 and 35 weeks of age. Samples were taken by indwelling jugular catheter (vinyl tubing SV-70, i.d. $1.00 \mathrm{~mm}$, o.d. $1.50 \mathrm{~mm}$; Dural Plastics and Engineering, Dural, NSW, Australia) inserted the day before treatment. Blood samples were allowed to clot at $21^{\circ} \mathrm{C}$, clots were removed and serum was stored at $-20^{\circ} \mathrm{C}$ until analysed.

Mating ability. Every 2 weeks, from 22 weeks of age, the lambs were checked for mating ability. Randomly chosen pairs were introduced to oestrogen-treated, ovariectomized ewes for $10-15 \mathrm{~min}$. Ram lambs mounting ewes and appearing to ejaculate were separated and semen collection was attempted 1 day later. Semen was collected using an artificial vagina and a restrained oestrogen-treated, ovariectomized ewe (Mickelsen $e t$ al., 1982). Semen was analysed for motility and sperm concentration, using accepted procedures (Roberts, 1986). Sexual maturity was defined as the time at which ram lambs were able to mount and ejaculate and semen characteristics fell in the lower end of the range for adult rams ( $>80 \%$ motility, $>1 \times 10^{9}$ spermatozoa $/ \mathrm{ml}$ of semen) (Roberts, 1986).

$\boldsymbol{L H}$ and FSH assay. Serum concentrations of $\mathrm{LH}$ and FSH were determined for all samples by radioimmunoassay and are expressed in terms of NIAMDD-oLH-24 and NIAMDD-oFSH-RP1, respectively (Currie \& Rawlings, 1989). All samples for each experimental period (treatment and control) were assayed together. Sensitivities of the assays, defined as the concentrations of the lowest standard different from zero $(P<0.05)$, were $0.06 \mathrm{ng} \mathrm{LH} / \mathrm{mlserum}$ and $0.08 \mathrm{ng}$ $\mathrm{FSH} / \mathrm{ml}$ serum. Intra- $(n=13)$ and interassay $(n=91)$ coefficients of variation for LH were $6 \cdot 3$ and $8 \cdot 1 \%$, respectively, for a reference serum (mean $=1.21 \mathrm{ng} / \mathrm{ml}$ ) replicated in every assay. Intra- $(n=13)$ and interassay $(n=91)$ coefficients of variation for FSH were 4.8 and $13.1 \%$, respectively, for a reference serum (mean $=2.0 \mathrm{ng} / \mathrm{ml}$ ) replicated in every assay.

Testosterone assay. Serum testosterone concentrations were estimated for each lamb, at each treatment, on a serum pool of samples taken once an hour over the sampling periods. Serum concentrations of testosterone were determined in a previously validated radioimmunoassay (Cook \& Rawlings, 1986), with samples batched for analysis as described for LH and FSH. Sensitivity was $0.03 \mathrm{ng} / \mathrm{ml}$. Intra- $(n=13)$ and interassay $(n=53)$ coefficients of variation were 11.6 and $17.7 \%$, respectively for a reference serum with a mean testosterone level of $0.79 \mathrm{ng} / \mathrm{ml}$. Testosterone concentrations are expressed as mean concentrations.

LH and FSH pulse amplitude and frequency. $\mathrm{LH}$ and FSH pulses were detected as values above basal LH by the method of Goodman \& Karsch (1980). LH and FSH data are expressed as mean and basal concentrations and as pulse amplitude and frequency. Basal values were determined by subtracting values determined to be within a pulse from the mean.

Statistical analysis. Data were analysed and are presented using 6-h periods at 5, 10 and 15 weeks of age and 8-h periods at 20,25, 30 and 35 weeks of age. Data were also analysed on a 6-h basis for all periods, but these results were not different from the original analysis. Data were analysed by two-way analysis of variance and Student-NeumanKeul's procedure. 


\section{Results}

Semen collection was possible in all ram lambs ejaculating during the mating test, although some would not serve an artificial vagina until their second positive mating test. Naloxone had no effect on the age at sexual maturity (controls $239 \pm 23$ days, naloxone-treated $232 \pm 33$ days).

Naloxone administration resulted in a greater $\mathrm{LH}$ pulse amplitude at 5 and 10 weeks of age and a dower basal LH concentration at 10 weeks of age (Fig. 1b,c) than in the controls, but had no effects on LH pulse frequency or mean LH concentrations in these young lambs. At 35 weeks of age, mean and basal LH concentrations and LH pulse amplitude were significantly higher with naloxone administration (Figs $1 \mathrm{a}, \mathrm{b}$ and $2 \mathrm{~d}$ ) than in the controls. The only effect of naloxone on LH pulse frequency was a greater value than in the controls at 25 weeks of age (Fig. 1d). Naloxone administration resulted in a greater FSH pulse amplitude than in the controls at 10 weeks of age (Fig. 3c).
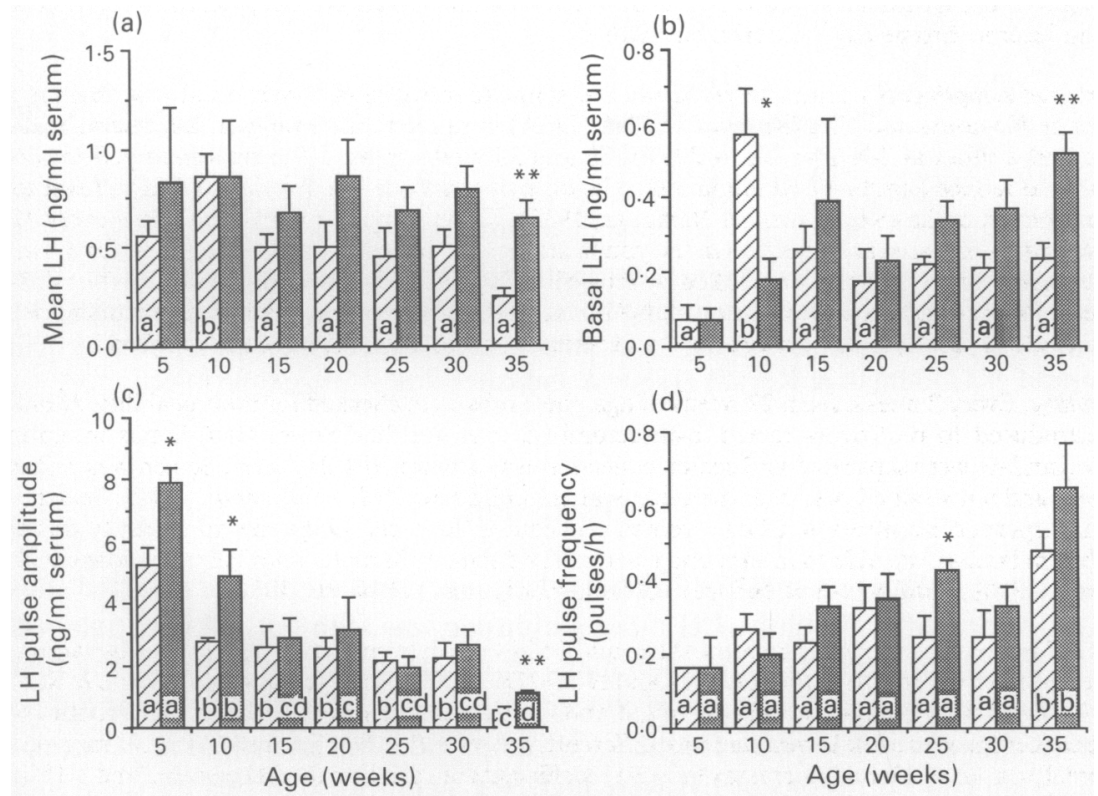

(d)

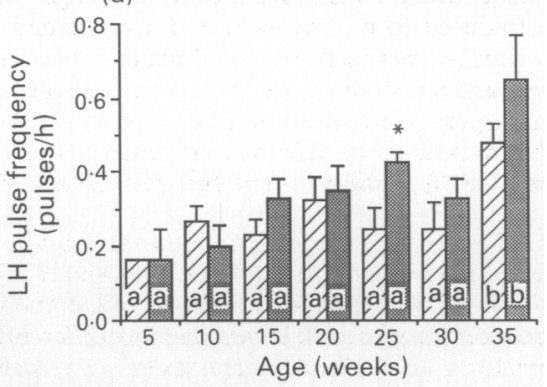

Fig. 1. (a) Mean and (b) basal serum concentrations of luteinizing hormone (LH) and (c) LH pulse amplitude and (d) frequency in ram lambs treated with saline ( $\mathbb{Z}$ ) or naloxone (国, $1 \mathrm{mg} / \mathrm{kg}$ in saline) at $5,10,15,20,25,30$ and 35 weeks of age. Data are means \pm s.e.m. Differences between treatment groups are significant: ${ }^{*} P<0.05$ or ${ }^{* *} P<0.01$. Columns, within each treatment group, with different subscripts are significantly different $(P<0.05)$.

In control, but not naloxone-treated lambs, basal and mean serum LH concentrations were highest at 10 weeks of age $(P<0.05$, Fig. 1a, b). LH pulse amplitude was highest in the 5 -week-old lambs (control and treated), falling to a low in 35-week-old animals $(P<0 \cdot 05$, Fig. 1c). In contrast, LH pulse frequency was greatest in 35-week-old lambs $(P<0.05$, Fig. 1d). Mean and basal serum FSH concentrations and FSH pulse amplitude were highest at 5 weeks of age $(P<0.05$, Fig. 3a, b, c) and fell subsequently, but FSH pulse frequency did not change with age $(P<0.05$, Fig. 3d). Serum testosterone concentrations rose with age, the highest occurring in 30- and 35-week-old control and treated lambs $(P<0.05$, Fig. 4). 
(a) At 10 weeks

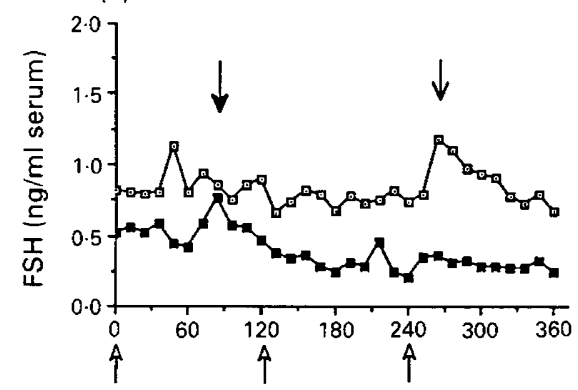

(c) At 30 weeks

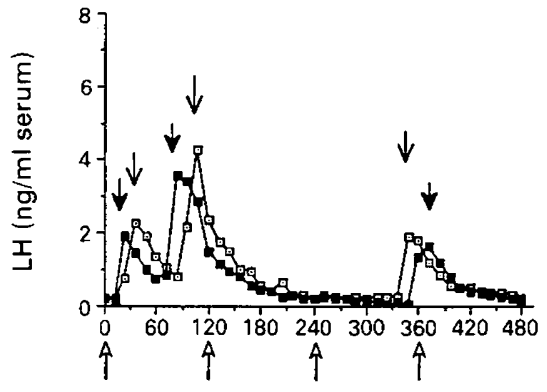

(b) At 10 weeks

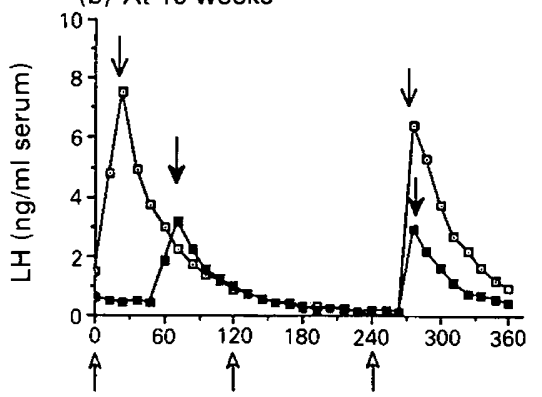

(d) At 35 weeks

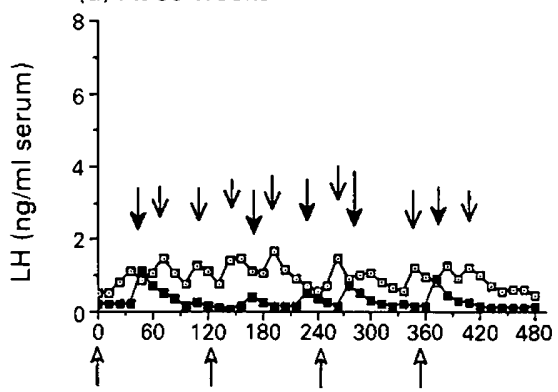

Duration of treatments $(\mathrm{min})$

Fig. 2. Representative profiles of serum concentrations ( $\mathrm{ng} / \mathrm{ml}$ serum) of (a) follicle-stimulating hormone (FSH) or (b, c and d) luteinizing hormone ( $\mathrm{LH})$ in ram lambs of different ages treated with saline $(\boldsymbol{\square}, \downarrow)$ or naloxone $(1 \mathrm{mg} / \mathrm{kg}$ in saline $)(\square, \downarrow)$; arrows indicate a pulse, as defined by the method of Goodman \& Karsch (1980) 4 indicates time of naloxone injection.

\section{Discussion}

In the present study, the age trends for LH pulse frequency and amplitude reflected those reported by Olster \& Foster (1986). Initially, LH pulse amplitude was high but fell with age, with a significant drop in the older, sexually mature animals. In contrast, LH pulse frequency rose with age, peaking in the mature lambs. Mean serum concentrations of LH in control lambs did not fluctuate in response to changes in LH pulse frequency or amplitude, but increased in 10-week-old lambs, when basal serum concentrations of $\mathrm{LH}$ were high; the significance of this transient increase is not clear, but it may reflect a temporary increase in the availability of LH for basal secretion, as LH pulse amplitude declines. Unlike LH, FSH pulse frequency did not change with age, nor was there a marked decline in FSH pulse amplitude in the sexually mature lambs. Yet, as with LH, FSH pulse amplitude was high in the young, sexually immature lambs. Mean and basal serum concentrations of FSH, unlike $\mathrm{LH}$, did not show a transient rise at 10 weeks of age. The change in serum testosterone concentrations with age resembles the pattern reported by Cook \& Rawlings (1986).

In the present study, the high mean and basal concentrations and pulse amplitude of serum $\mathrm{LH}$ and FSH in the young lambs occurred when circulating testosterone concentrations were minimal. The subsequent decline in values for these gonadotrophin parameters was probably a result of the establishment of testosterone negative-feedback control. However, after a major increase in serum concentrations of testosterone, LH pulse amplitude fell significantly in mature lambs, while LH and FSH pulse frequencies did not change; LH pulse frequency was highest in 35-week-old lambs. This suggests that, if sexual maturity is achieved as a result of a lowering of hypothalamic/pituitary feedback sensitivity to androgens, this process only involves LH pulse frequency, supporting the findings of Olster \& Foster (1986). The increase in circulating concentrations of testosterone 
(a)

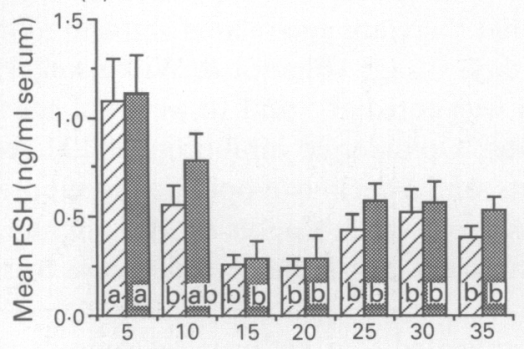

(c)

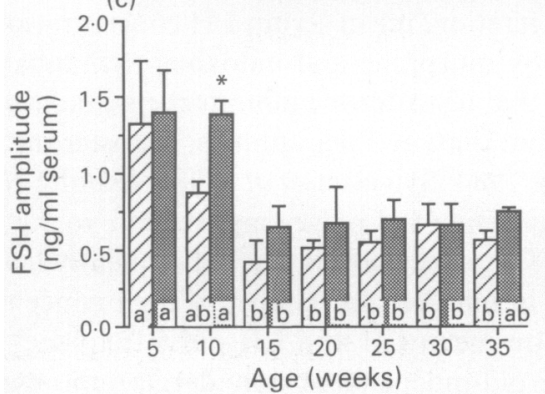

(b)

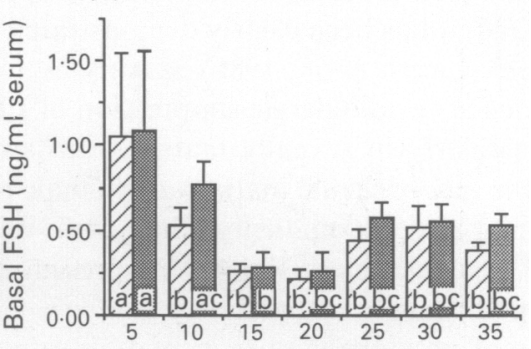

(d)

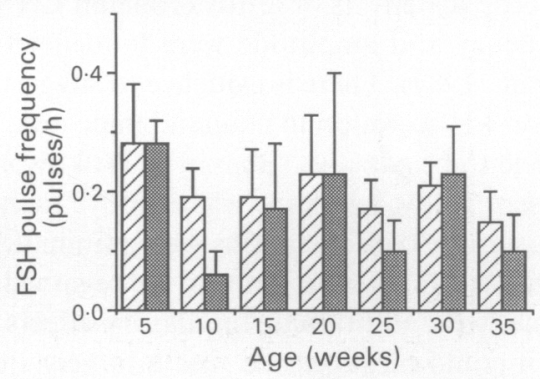

Fig. 3. (a) Mean and (b) basal serum concentrations of follicle-stimulating hormone (FSH) and (c) FSH pulse amplitude and (d) frequency in ram lambs treated with saline ( $\square$ ) or naloxone (圈, $1 \mathrm{mg} / \mathrm{kg}$ in saline) at $5,10,15,20,25,30$ and 35 weeks of age. Data are means \pm s.e.m. Differences between treatment groups are significant: ${ }^{*} P<0.05$ or ${ }^{* *} P<0.01$. Columns, within each treatment group, with different subscripts are significantly different $(P<0.05)$.

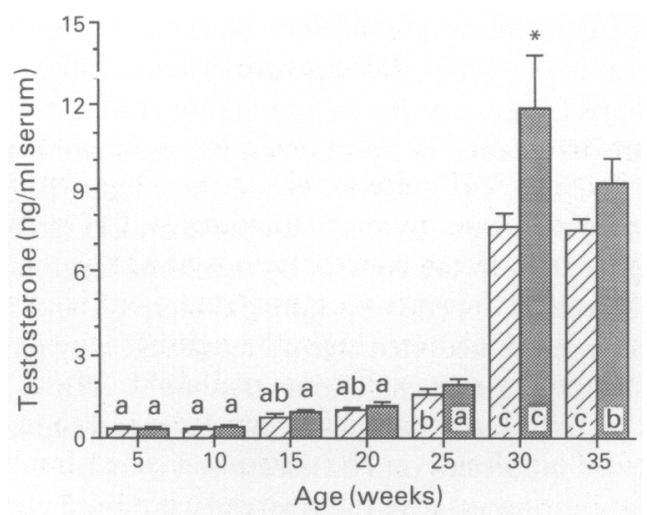

Fig. 4. Mean concentrations of testosterone in ram lambs treated with saline ( $\square$ ) or naloxone (, $1 \mathrm{mg} / \mathrm{kg}$ in saline) at $5,10,15,20,25,30$ and 35 weeks of age. Data are means \pm s.e.m. Differences between treatment groups are significant at ${ }^{*} P<0.05$. Columns, within each treatment group, with different subscripts are significantly different $(P<0.05)$.

appears to be driven by increasing LH pulse frequency; Olster \& Foster (1986) showed an earlier, as well as a later, rise in $\mathrm{LH}$ pulse frequency in developing ram lambs, closely paralleling the rise in testosterone concentrations with age noted in the present study.

In prepubertal male rats, naloxone appeared to be effective in increasing serum concentrations of LH to values higher than in controls by 30 days of age; sensitivity to naloxone appeared to increase thereafter up to sexual maturity (Cicero et al., 1986). It has been suggested that opioidergic 
sensitivity may decrease as sexual maturity approaches (Bhanot \& Wilkinson, 1983; Cicero et al., 1986). Indeed, it has been clearly demonstrated that there are age-related shifts in morphine sensitivity of LH (Cicero et al., 1986) as early as 15 days of age (Bhanot \& Wilkinson, 1983). In this study, evidence of opioidergic suppression of LH was noted at 5 and 10 weeks of age and again in older, particularly in sexually mature, ram lambs. Opioidergic inhibition of LH secretion may influence the rate of sexual maturation in male rats, and a decline in opioidergic suppression of LH secretion may precede maturity (Bhanot \& Wilkinson, 1983; Zagon \& McLaughlin, 1984). The pattern of responsiveness seen in the present study did not indicate a decrease in sensitivity to naloxone preceding sexual maturity.

Results of previous studies in mature rams indicated that endogenous opioids mediated the negative-feedback effects of testosterone on LH secretion; mean serum LH concentrations and LH pulse frequency and amplitude were influenced by morphine and naloxone (Schanbacher, 1985; Lincoln et al., 1987). There is evidence to suggest that testosterone inhibits the stimulatory effect of naloxone on LH secretion in neonatal male rats, but that, in older animals, testosterone is required for naloxone to be effective (Bhanot \& Wilkinson, 1984; Sylvester et al., 1984; Schultz et al., 1985). In the present study, naloxone was effective in increasing $\mathrm{LH}$ pulse amplitude in young ram lambs when testosterone concentrations were minimal. This effectiveness was subsequently lost as testosterone concentrations rose, only to be regained in mature ram lambs, at high concentrations of testosterone, with additional stimulatory effects on mean $\mathrm{LH}$ and $\mathrm{LH}$ pulse frequency. Based on our data, it could be suggested that a largely steroid-independent opioidergic suppression of LH occurs in very young males, which is later replaced in mature animals by a more general, and largely steroid-dependent inhibition of LH secretion. It could also be argued that the effects of naloxone are initially lost or masked as the animal grows, because of the establishment of testosterone-dependent, opioid-independent negative feedback; whereas in mature animals a component of testosterone feedback has to be opioid dependent. The inhibitory effect of naloxone on basal LH secretion at 10 weeks of age cannot be ignored. This effect appeared briefly at an age when basal LH secretion was high, at least in control ram lambs. Although opiates are largely regarded as having inhibitory effects on LH secretion, stimulatory effects have been noted (Limonta et al., 1987; Currie et al., 1988; Van Vugt et al., 1989). Opioidergic systems appear to be involved in the early transitions in $\mathrm{LH}$, and perhaps FSH, secretion in young ram lambs, but further elucidation of their significance and mechanisms is needed. In adult ewes, naloxone and morphine did not influence FSH secretion (Currie \& Rawlings, 1987, 1989). While the effects of naloxone on FSH secretion were evident in this study, they were less obvious than those on LH secretion. FSH pulse amplitude was increased to values higher than in the control by naloxone treatment at 10 weeks of age. The feedback control of FSH secretion depends on gonadal steroids and inhibin. This lesser dependency on steroids, and hence opioid-mediated steroid feedback, may partly explain the differential sensitivity of LH and FSH secretion to naloxone treatment. While some steroid-independent opioidergic effects on FSH secretion may be evident in very young animals, when inhibin secretion is presumably low, opioidergic influences on FSH secretion in mature ram lambs cannot be ruled out. The appearance, though not necessarily the removal, of opioid control may be an important indicator, if not instigator, of pubertal processes in male ram lambs.

We thank S. Cook for technical assistance and M. Buckley and her staff for assistance with animal care. This work was supported by a grant from NSERC. Naloxone was generously provided by DuPont Pharmaceuticals. Standards for the LH assays and the FSH assay system were provided by NIAMDD. LH for iodinations was provided by Dr L. E. Reichert, Jr.

\section{References}

Bhanot, R. \& Wilkinson, M. (1983) Opiatergic control of gonadotropin secretion during puberty in the rat: a neurochemical basis for the hypothalamic 'gonadostat'? Endocrinology 113, 596-603. 
Bhanot, R. \& Wilkinson, M. (1984) The inhibitory effect of opiates on gonadotrophin secretion is dependent upon gonadal steroids. J. Endocr. 102, 133-141.

Cicero, T.J., Schmocker, P.F., Meyer, E.R., Miller, B.T., Bell, R.D., Cytron, S.M. \& Brown, C.C. (1986) Ontogeny of the opioid-mediated control of reproductive endocrinology in the male and female rat. $J$. Pharmacol. exp. Ther. 236, 627-633.

Cook, S.J. \& Rawlings, N.C. (1986) Serum androgen and gonadotropin profiles over the first year of life in ram lambs and the effect of season of birth. Can. J. Anim. Sci. 66, 67-75.

Currie, W.D. \& Rawlings, N.C. (1987) Naloxone enhances LH but not FSH during various phases of the estrous cycle in the ewe. Life Sci. 41, 1207-1214.

Currie, W.D. \& Rawlings, N.C. (1989) Fluctuation in responsiveness of $\mathrm{LH}$ and lack of responsiveness of FSH to prolonged infusion of morphine and naloxone in the ewe. J. Reprod. Fert. 86, 359-366.

Currie, W.D., Rawlings, N.C. \& Cook, S.J. (1988) Divergent response of $\mathrm{LH}$ to morphine in the ovariectomized ewe. In Proc. 1lth Int. Congr. Anim. Reprod. \& $A I$, brief communication No. 19. Dublin, Ireland.

Ebling, F.J.P. \& Lincoln, G.A. (1985) Endogenous opioids and the control of seasonal LH secretion in Soay rams. J. Endocr. 107, 341-353.

Goodman, R.L. \& Karsch, F.J. (1980) Pulsatile secretion of luteinizing hormone: differential suppression by ovarian steroids. Endocrinology 107, 1286-1290.

Ieiri, T., Chen, H.T. \& Meites, J. (1978) Effects of morphine and naloxone on serum levels of luteinizing hormone and prolactin in prepubertal male and female rats. Neuroendocrinology 29, 288-292.

Limonta, P., Maggi, R., Dondi, D., Martini, L. \& Piva, F. (1987) Gonadal steroid modulation of brain opioid systems. J. Steroid Biochem. 27, 691-698.
Lincoln, G.A., Ebling, F.J.P. \& Martin, G.B. (1987) Endogenous opioid control of pulsatile LH secretion in rams: modulation by photoperiod and gonadal steroids. J. Endocr. 115, 425-438.

Mickelsen, W.D., Paisley, L.G. \& Dahmen, J.J. (1982) The relationship of libido and serving capacity test scores in rams on conception rates and lambing percentage in the ewe. Theriogenology 18, 79-86.

National Research Council (1985) Nutrient Requirements of Sheep, 6th edn. National Academy Press, Washington, DC.

Olster, D.H. \& Foster, D.L. (1986) Control of gonadotropin secretion in the male during puberty: a decrease in response to steroid inhibitory feedback in the absence of an increase in steroid independent drive in the sheep. Endocrinology 118, 2225-2234.

Roberts, S.J. (1986) Veterinary Obstetrics and Genital Diseases. Edwards Bro. Inc., Ann Arbor, MI.

Schanbacher, B.D. (1985) Endogenous opiates and the hypothalamic-pituitary gonadal axis in male sheep. Dom. Anim. Endocr. 2, 67-75.

Schulz, R., Wilhelm, A., Pirke, K. M. \& Herz, A. (1985) Sex-dependent endorphinergic and adrenergic control mechanisms of luteinizing hormone secretion in immature rats. Acta Endocr. 109, 198-203.

Sylvester, P.W., Sarkar, D.K., Briski, K.P. \& Meites, J. (1984) Relation of gonadal hormones to differential LH response to naloxone in prepubertal male and female rats. Neuroendocrinology 40, 165-170.

Van Vugt, D.A., Baby, N., Stewart, M. \& Reid, R.L. (1989) The paradoxical stimulatory effect of morphine on $\mathrm{LH}$ secretion is dose-dependent and naloxone reversible. Neuroendocrinology 50, 109-116.

Zagon, I.S. \& McLaughlin, P.J. (1984) Naltrexone modulates body and brain development in rats: a role for endogenous opioids in growth. Life Sci. 35, 2057-2064.

Received 25 September 1990 